\title{
Salicylate-mediated interactions between pathogens and herbivores
}

\author{
Jennifer S. Thaler, ${ }^{1,2,3}$ Anurag A. Agrawal, ${ }^{1,2}$ and Rayko Halitschke ${ }^{2}$ \\ ${ }^{1}$ Department of Entomology, 4138 Comstock Hall, Cornell University, Ithaca, New York 14853 USA \\ ${ }^{2}$ Department of Ecology and Evolutionary Biology, 4138 Comstock Hall, Cornell University, Ithaca, New York 14853 USA
}

\begin{abstract}
Plants employ hormone-mediated signaling pathways to defend against pathogens and insects. We tested predictions about the relative effect of jasmonate and salicylate pathways and how they mediate interactions between pathogens and herbivores. We employed two pathogens of tomato, Pseudomonas syringae (Pst) and tobacco mosaic virus (TMV), that are known to elicit distinct components of the two pathways, and we address the consequences of their induction for resistance in wild-type and salicylate-deficient transgenic plants in field experiments. We report that $P s t$ infection induced jasmonic acid and proteinase inhibitors (PIs), and reduced the growth of Spodoptera exigua caterpillars on wild-type and salicylate-deficient plants. Pst and TMV both induced salicylic acid in wild-type but not salicylate-deficient plants. Although TMV did not affect jasmonic acid or PIs, infection increased caterpillar growth on wild-type plants, but not on salicylate-deficient plants. Aphid population growth was higher on salicylate-deficient compared to wild-type plants, and lower on salicylate-induced plants compared to controls. Natural aphid colonization was reduced on TMV-infected wild types, but not on salicylate-deficient plants. In sum, jasmonate-mediated resistance is induced by some pathogens, independent of salicylate, and salicylate-mediated induction by other pathogens results in induced susceptibility to a chewer and resistance to an aphid. We conclude with a predictive model for the expression of defense pathways and their consequences.
\end{abstract}

Key words: BTH, benzothiadiazole; chemical ecology; signaling cross talk; jasmonic acid; nahG; plantinsect interactions; Pseudomonas syringae; proteinase inhibitor; salicylic acid; systemic acquired resistance; tobacco mosaic virus; tomato Solanum lycopersicum.

\section{INTRODUCTION}

The recent elucidation of plant defense-signaling pathways has allowed for a novel level of predictability for the ecological outcomes of specific plant-enemy interactions (Howe 2004, Stout et al. 2006). Induced changes in plants following herbivore and pathogen attack can mediate interactions between any two organisms that share a host plant (McIntyre et al. 1981, Karban et al. 1987, Hatcher 1995). For example, early-season attack by one herbivore may elicit a plant physiological response that results in competition or facilitation with later-season herbivores (Van Zandt and Agrawal 2004, Ohgushi 2005, Viswanathan et al. 2005). Knowing the responses that particular enemies induce (specificity of elicitation) and the impact of these responses for various enemies (specificity of effect) can thus result in a mechanistic understanding of ecological interactions (Stout et al. 1998, 2006).

Several groups have been studying the jasmonate and salicylate responses of tomato plants Solanum lycopersicum (Thaler et al. 2002, 2004, O'Donnell et al. 2003, Cooper and Goggin 2005, Chen et al. 2006, Lin et al. 2008). In particular, early work established a role for

Manuscript received 19 December 2008; revised 8 June 2009; accepted 4 July 2009. Corresponding Editor: M. P. Ayres.

3 E-mail: thaler@cornell.edu salicylate-mediated responses in plant resistance to pathogenic microbes (Raskin 1992, Brading et al. 2000) and jasmonate-mediated responses in resistance to insect herbivores (Farmer et al. 1992, Thaler et al. 2001). However, several lines of evidence suggest that this dichotomy is too simplistic. First, there is "cross talk" or reciprocal down-regulation of each of these responses by the other (Doares et al. 1995, Thaler et al. 1999, 2002, Ton et al 2002, Cui et al. 2005, Zarate et al. 2007). Second, some herbivores induce a salicylatedependent response (Kaloshian and Walling 2005, Musser et al. 2005) and some microbial pathogens induce jasmonate-mediated responses (Stout et al. 1998, Fidantsef et al. 1999, Thomma et al. 2001, Spoel et al. 2007). Finally, jasmonate-induced responses have been shown to be essential for plant resistance to several microbial pathogens (O’Donnell et al. 2003, Thaler et al. 2004, Stout et al. 2006) and salicylate has been implicated in resistance to some herbivores (Inbar et al. 1998, Walling 2000, Cooper et al. 2004). Thus, the dichotomy of jasmonate-induction by, and impact on, insect herbivores, and salicylate induction by, and impact on, pathogens, has given way to knowledge of greater complexity in such interactions.

To unravel this complexity and work toward using knowledge of the specific plant responses and their effects, it would be useful to (1) categorize plant attackers by their elicitation of specific plant responses 
and (2) directly implicate plant-mediated defense responses in the interaction between potential enemies on the same host. To address the first issue, attempts have been made to understand whether herbivores and pathogens from specific feedings guilds are more likely to be associated with inducing jasmonate or salicylate (Walling 2000). Chewing lepidopteran herbivores have been associated largely with the jasmonate response, while herbivory by phloem-sucking hemipterans is often associated with the salicylate response and a somewhat weaker jasmonate response (Moran and Thompson 2001, Rodriguez-Saona et al. 2005, Thompson and Goggin 2006). For microbial pathogens, similar groups can be delineated. While biotrophic fungal pathogens and tobacco mosaic virus (TMV) primarily induce salicylate (Tornero et al. 1997, Thomma et al. 2001, Stout et al. 2006), some necrotrophic pathogens including the bacterial speck Pseudomonas syringae (Pst; see Plate 1) induce both a jasmonate and salicylate response (Stout et al. 1998, Preston et al. 1999, Thaler et al. 2004).

The second issue is that pathogens and herbivores interact in many ways on plants. Both direct interactions (e.g., herbivores avoiding eating fungal hyphae) as well as indirect interactions (e.g., changes in host plant quality or volatile emissions) are possible. A useful tool to isolate the effects of particular defensive pathways is to use genetically modified plants that are disabled in individual signaling components (Cipollini et al. 2004, Kessler et al. 2004, Thaler et al. 2004, Zarate et al. 2007). If a particular interaction occurs on wild types but is altered on plants disabled in a specific signal pathway, it is reasonable to conclude that the pathway mediates the interaction.

We sought to address the role of a specific plant defense response, the salicylate pathway, in mediating the interaction between pathogens and herbivores. To study such interactions, we conducted field and laboratory experiments using wild-type and salicylate-deficient plants and two pathogens and two herbivores from divergent feeding guilds. TMV and Pst were chosen as plant attackers because of their known differential effect on induced responses. Both pathogens cause many changes in the plant physiology, with TMV primarily inducing the salicylate pathway in tomato plants (Tornero et al. 1997), while Pst infection induces both a salicylate and jasmonate response (Stout et al. 1998, Fidantsef et al. 1999). Effects of these pathogen-induced responses were measured on the chewing herbivore, Spodoptera exigua, because it is susceptible to the jasmonate-, but not salicylate-dependent responses (Thaler et al. 1999). Thus, we predicted that Pst would induce resistance to $S$. exigua on both wild-type and salicylate-deficient plants, and that TMV would induce susceptibility to $S$. exigua, but only on wild-type plants (where the jasmonate signaling pathway would be suppressed by the induced salicylate response).
We also addressed the consequences of salicylate pathway-dependent responses for phloem-sucking hemipterans (aphids) because they have been associated with inducing salicylate responses, yet effects of jasmonate and salicylate responses on phloem feeders are relatively unknown and somewhat conflicting between plant systems (Kaloshian and Walling 2005). Jasmonate-dependent responses in Arabidopsis and tomato have a negative effect on Myzus persicae (green peach aphid) and Macrosiphum euphorbiae (potato aphid), respectively (Inbar et al. 1998, 2001, Thaler et al. 2001, Ellis et al. 2002), but sometimes this effect is weak (Boughton et al. 2006), depends on the plant cultivar (Cooper et al. 2004), or affects adult preference but not performance (Bhattarai et al. 2007). Inducing the salicylate pathway using the salicylate mimic benzothiadiazole (BTH) has also been shown to reduce fecundity of $M$. persicae (Boughton et al. 2006) and $M$. euphorbiae (Cooper et al. 2004) on tomato. $M$. euphorbiae has higher longevity on salicylate-deficient tomato plants ( $\mathrm{Li}$ et al. 2006); together these studies show a different pattern than is seen on Arabidopsis (Thompson and Goggin 2006). Thus, our specific goal was to pinpoint any role for the salicylate pathway in resistance to two herbivores, a caterpillar and an aphid, and to show how effects of particular pathogens may be predicted from knowledge of the pathways they induce. Specifically, we conducted (1) field experiments to test the effect of the two pathogens on caterpillar performance and aphid abundance on wild-type and salicylatedeficient plants, (2) a greenhouse experiment to measure the plant hormonal response to each pathogen, and (3) a greenhouse experiment to measure aphid performance on plants that over- and under-express salicylate.

\section{Materials and Methods}

Salicylate deficiency, pathogen infection, and $\mathrm{S}$. exigua performance.-We hypothesized that if the salicylate pathway was involved in plant resistance to herbivores, then this would be revealed by differentially induced resistance in plants with and without an intact salicylate response. We employed wild-type tomatoes (Solanum lycopersicum cv Moneymaker) and a genetically engineered line of cv Moneymaker (with the nahG transgene) where salicylic acid is converted to catechol, a compound without salicylate function (Brading et al. 2000). Plants were germinated in the lab and transplanted to a plowed field at the Koffler Scientific Reserve at Joker's Hill, King City, Ontario, at the two-true-leaf stage. Permits were obtained to grow genetically modified plants in the field (Canadian Food Inspection Agency 02-UOT1-228-TOM). Plants of the two lines were randomized and grown in the field for 5 days and then were inoculated with either Pst or TMV, or were mock-treated as controls.

Pseudomonas syringae pv tomato DC3000 was incubated at $27^{\circ} \mathrm{C}$ for $48 \mathrm{~h}$ on King's B medium and colonies were suspended in sterile water. The terminal leaflet of 
leaf two was lightly dusted with carborundrum, painted with $1 \mathrm{~mL}$ of an aqueous suspension of $10^{7}$ colonyforming units, and gently rubbed. One leaf of Xanthi tobacco infected with TMV was ground in ice-cold buffer (0.1 mol/L KPhos buffer $\mathrm{pH}$ 7.2) and inoculated as previously described. Control plants were rubbed with carborundrum and $1 \mathrm{~mL}$ of water in the same manner as the inoculated plants. Two weeks after $P s t$ inoculation, the degree of disease was measured on the plants as the number of leaves with signs of necrosis and the total necrotic leaf area $\left(\mathrm{mm}^{2}\right)$.

We examined whether the effect of pathogen infection is distinct on the two types of plants for induction of proteinase inhibitors (PIs, a marker of jasmonateinduced responses) and for the performance of S. exigua caterpillars. Seven days after pathogen inoculation, leaves were collected for chemical and biological assays. The terminal leaflet of the fourth leaf was excised with a razor blade, placed on ice, and stored in a $-80^{\circ} \mathrm{C}$ freezer. Measurement of PI activity followed Thaler et al. (1996), modified for analysis in 96-well plates. The terminal leaflet of the third leaf was collected for bioassays in petri dishes lined with moist filter paper. A single newly hatched S. exigua caterpillar was allowed to feed on each leaflet for 3 days before it was weighed.

Two trials of this experiment were conducted, one in June and July. For each trial, there were 25-35 replicates of the TMV and Pst treatments and 15-20 of the control treatments per plant type (total $n=315$ plants). We collected a subset (7-8 replicates per treatment) for chemical analysis. Factorial two-way ANOVA was used to assess the effects of plant line and pathogen infection on caterpillar growth and plant chemistry. Contrasts were conducted on treatments within plant type as the salicylate-deficient plants grew less than wild-type plants, independent of pathogen treatment. Residuals were examined for meeting the assumptions of ANOVA and data were transformed as indicated.

Pathogen infection and phytohormone induction.Previous research suggested that Pst would induce both the jasmonate and salicylate pathways, whereas TMV would only induce the salicylate pathway. We confirmed this by inoculating wild-type and salicylate-deficient plants with the two pathogens and measuring subsequent JA and SA levels. Plants were grown for three weeks in the greenhouse and were then inoculated with Pst, TMV or controls as just described. Tissue from inoculated leaves was collected 24 and $48 \mathrm{~h}$ following inoculation $(n=4-5$ per treatment per plant type). Tissue was immediately placed in liquid nitrogen and then stored at $-80^{\circ} \mathrm{C}$ until chemical analysis. Data were transformed as $\ln (x+1)$ to equalize variance between treatments and were analyzed using one-way ANOVA on each plant type, followed by contrasts. Because there was no effect of collection time, the two time points were pooled for statistical analysis.

Jasmonate and salicylate were extracted from the treated leaves as described in Pan et al. (2001), with the

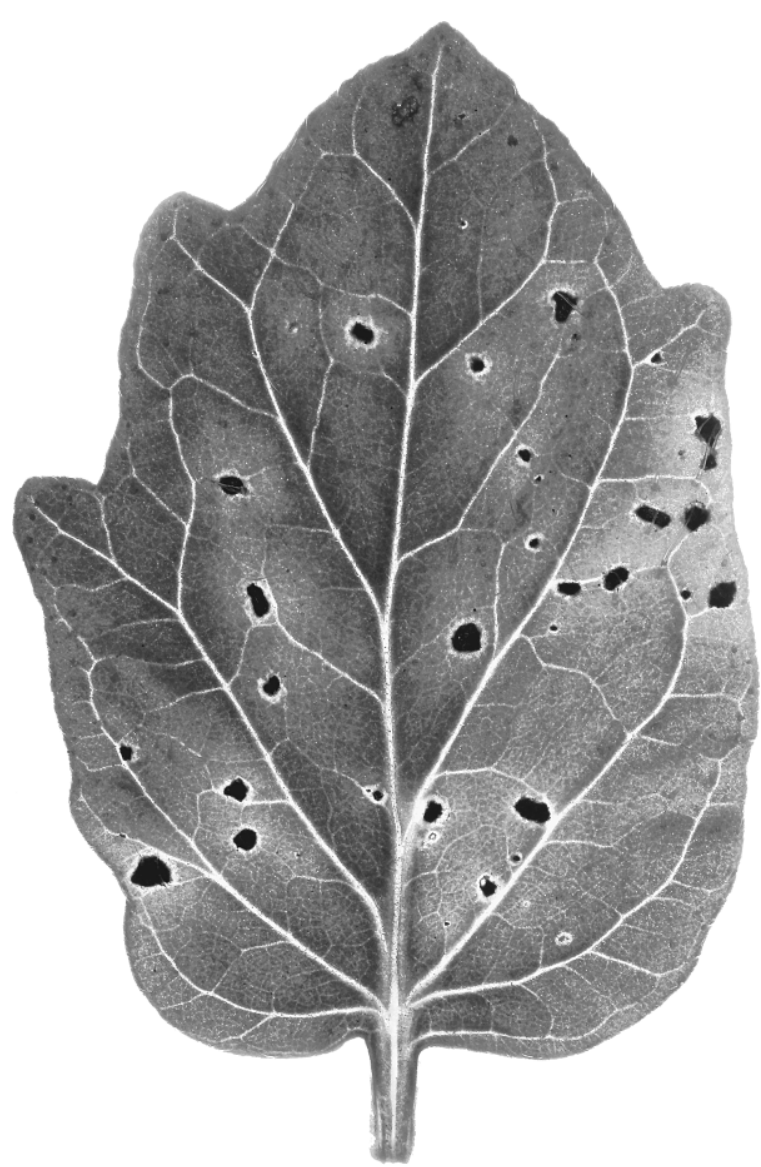

Plate 1. Pseudomonas syringae infecting a tomato leaflet. Photo credit: Kent Loeffler.

following modification of the extraction procedure. Frozen samples were transferred into 2-mL screw cap tubes containing $900 \mathrm{mg}$ zirconia/silica beads (BioSpec, Bartelsville, OK, USA) and $1 \mathrm{~mL}$ extraction buffer. $\mathrm{d}_{4}$-SA and $\mathrm{d}_{5}$-JA (CDN isotopes, Point-Claire, Canada) were added as internal standards and samples were homogenized in a FastPrep homogenizer (MP Biomedicals, Solon, Ohio, USA) at $6 \mathrm{~m} / \mathrm{s}$ for $45 \mathrm{~s}$. Samples were dissolved in $200 \mu \mathrm{L}$ methanol after extraction with dichloromethane and solvent evaporation and 15 $\mu \mathrm{L}$ were analyzed on a triple-quadrupole LC-MS/MS system (Quantum Access; Thermo Scientific, Waltham, Massachusetts, USA). Analytes were separated on a C18 reversed-phase HPLC column (Gemini-NX, $3 \mu, 150 \times$ $2.00 \mathrm{~mm}$; Phenomenex, Torrance, California, USA) using a gradient of $0.1 \%$ formic acid in water (solvent A) and $0.1 \%$ formic acid in acetonitrile (solvent B) at a flow rate of $300 \mu \mathrm{L} / \mathrm{min}$. The initial condition of $10 \%$ B was kept for $2 \mathrm{~min}$ and increased to $100 \%$ solvent B at $20 \mathrm{~min}$. Phytohormones were analyzed by negative electrospray ionization (spray voltage: $3.5 \mathrm{kV}$; sheat gas: 15 ; auxiliary gas: 15 ; capillary temperature: $350^{\circ} \mathrm{C}$ ), collision-induced dissociation (argon CID gas pressure 1.3 mTorr [1.3 micron $\mathrm{Hg}$ ], CID energy $16 \mathrm{~V}$ ) and selected reaction 

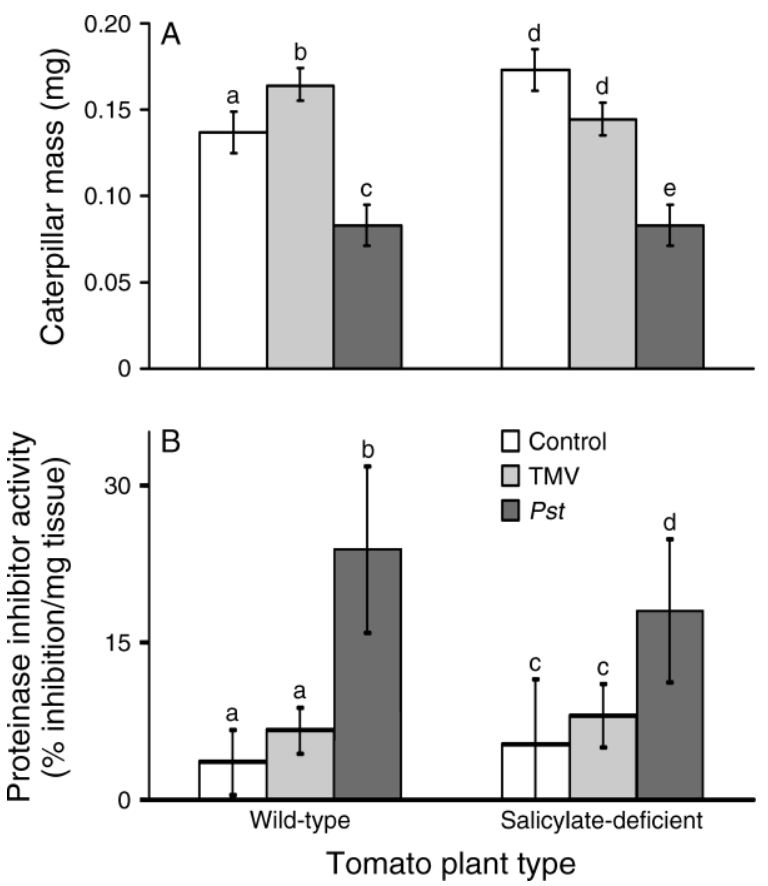

FIG. 1. (A) Growth of Spodoptera exigua caterpillars and (B) proteinase inhibitor activity (measured as the percentage inhibition of chymotrypsin activity relative to a control run with chymotrypsin and substrate only), comparing wild-type and salicylate-deficient tomato plants (Solanum lycopersicum) treated with either tobacco mosaic virus (TMV) or Pseudomonas syringae (Pst) in the field vs. control. Values are means \pm SE. Different letters indicate significant differences $(P$ $<0.05)$ within plant type using contrasts.

monitoring (SRM) of compound-specific parent/product ion transitions: SA $137 \rightarrow 93$; $\mathrm{d}_{4}$-SA $141 \rightarrow 97$; JA $209 \rightarrow 59$; $\mathrm{d}_{5}$-JA $214 \rightarrow 62$.

Impacts of salicylate responses on aphids.-In a separate field experiment, we treated wild-type and salicylate-deficient plants with or without TMV and examined subsequent colonization by Myzus persicae (total $n=121$ plants). All colonizing insects were counted, but aphids were the only insects that reached appreciable numbers. We predicted that TMV would induce resistance to aphids, but only on wild-type plants because resistance is known to be salicylate-mediated. Plants were grown and treated as previously described. Plant height and aphid abundance were determined for each plant after 7 days. Analysis was with two-way ANOVA, with plant height included as a covariate.

An additional laboratory experiment was conducted to test the specific effects of the salicylate pathway on aphid reproduction, as the field experiment combined effects on preference (colonization) and reproduction. We employed salicylate-deficient plants, wild-type plants, and wild-type plants induced with BTH to increase salicylate expression (Inbar et al. 1998) (total $n=96$ plants). Wild-type and salicylate-deficient plants were grown in the greenhouse until the four-leaf stage. Wild-type plants were divided into two groups: the third leaf of one group was treated with $1.2 \mathrm{mmol} / \mathrm{L} \mathrm{BTH}$ and the third leaf of the other group was treated with 1.2 $\mathrm{mmol} / \mathrm{L}$ of the BTH carrier as a control. Salicylatedeficient plants were treated with carrier only. Two days after treatment, the third leaf of each plant was enclosed in a polyester sleeve and two 7-day-old Macrosiphum euphorbiae were placed in each sleeve. Seven days later, we counted the number of aphids. Because some plants with the nahG transgene spontaneously induce necrotic lesions (in the absence of infection), necrosis was measured, and only plants with less than 5\% leaf tissue necrosis were used.

\section{RESUlts}

Salicylate deficiency, pathogen infection, and S. exigua performance.-Pst infection reduced the growth of $S$. exigua larvae $>50 \%$ on both the wild-type and salicylate-deficient plants compared to controls and TMV-infected plants (Fig. 1A and Appendix). This effect occurred despite greater Pst symptoms on the salicylate-deficient plants, with twice the number of infected leaves (wild-type $1.2 \pm 0.107$ leaves, mean \pm SE; salicylate-deficient $2.3 \pm 0.239$ leaves; $F_{1,29}=18.93$, $P<0.001$ ) and twice the infected area (wild-type 78.13 $\pm 12.8 \mathrm{~mm}^{2}$, mean $\pm \mathrm{SE}$; salicylate-deficient $142.7 \pm$ $19.83 \mathrm{~mm}^{2} ; F_{1,29}=7.41, P=0.011$ ) on salicylate-deficient compared to wild-type plants.

The effect of TMV infection on $S$. exigua growth was reversed on the salicylate-deficient plants compared to wild types. Across the two trials of the experiment, TMV caused a $20 \%$ increase effect on S. exigua growth compared to controls on the wild types, but there was a $17 \%$ decrease when caterpillars were on the salicylatedeficient plants. Although the $17 \%$ decrease was not significant in the contrast within plant type, the interaction term between plant type and treatment was significant $(P=0.011)$, indicating that plant types differentially responded to infection (see Appendix). In a separate analysis using only control and TMV-infected plants, the interaction term for plant type and TMV persisted $\left(F_{1,200}=8.46, P=0.004\right)$. No visual symptoms of systemic TMV infection were observed.

The effects of infection on PI activity were significant for both plant types, and the effects of Pst on chemistry matched ecological effects on S. exigua (Fig. 1B and Appendix). PI activity in the uninfected control plants was equal on the wild-type and salicylate-deficient plants. Pst induced PI activity equally on both plant types, consistent with the negative effects of Pst on $S$. exigua on both plant types (effect of Pst, $F_{1,36}=11.61$, $P=0.002 ;$ Pst $\times$ plant type, $\left.F_{1,36}=0.057, P=0.81\right)$. TMV did not induce PI activity on either plant type (effect of TMV, $F_{1,33}=0.14, P=0.71$; TMV $\times$ plant type, $\left.F_{1,33}=0.58, P=0.96\right)$, but did increase growth of $S$. exigua on the wild types and decreased it on salicylate-deficient plants. This latter result indicates that much of the effect of salicylate pathway induction by TMV on caterpillars is independent of PIs. Many 

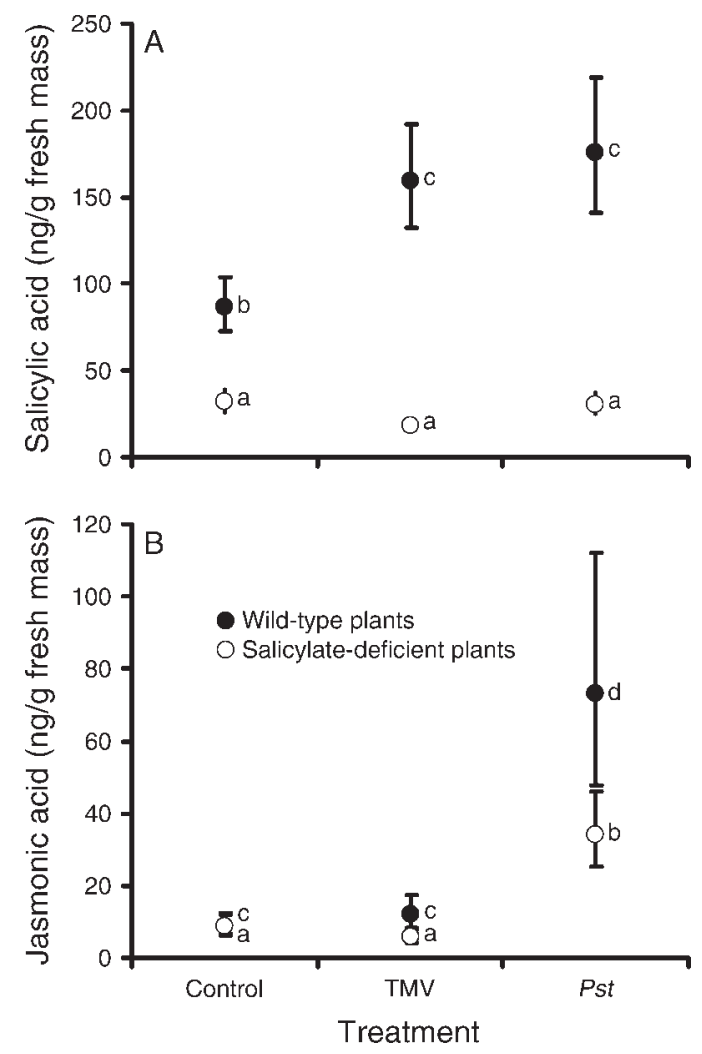

FIg. 2. The impact of tobacco mosaic virus (TMV) or Pseudomonas syringae (Pst) infection on (A) salicylic acid (SA) and (B) jasmonic acid (JA) pools in wild-type or salicylatedeficient plants. Shown are back-transformed means \pm SE. Different letters indicate significant differences $(P<0.05)$ within plant type using contrasts.

other important JA-regulated responses that could be differentially affected in TMV-infected wild-type and salicylate-deficient plants were not measured.

Pathogen infection and phytohormone induction.-As expected, Pst strongly induced jasmonic acid in wildtype plants (effect of infection, $F_{2,28}=8.71, P=0.001$ ) and salicylate-deficient plants $\left(F_{2,26}=9.46, P=0.001\right.$; Fig. 2). Pst and TMV each induced salicylic acid twofold in wild-type plants $\left(F_{2,28}=4.36, P=0.022\right)$, but there was no impact of infection on salicylate-deficient plants $\left(F_{2,26}=0.87, P=0.432\right)$. TMV did not induce JA in either plant type (Fig. 2).

Salicylate alteration and aphids.-Aphid colonization of field plants was reduced by TMV infection on wildtype plants but was unaffected by TMV on salicylatedeficient plants (plant $\times$ infection interaction, $F_{1,115}=$ 6.97, $P=0.009$; height covariate, $F_{1,115}=6.75, P=0.011$; main effects not significant; Fig. 3A). In the laboratory, aphids were negatively affected by salicylate pathway induction, as reproduction was $23 \%$ lower on wild-type plants treated with $\mathrm{BTH}$, and $23 \%$ higher on salicylatedeficient plants compared to untreated wild types $\left(F_{2,93}\right.$ $=12.2, P<0.001 ;$ Fig 3B).

\section{DisCUSSION}

It is clear that the dichotomy between jasmonate responses as a defense against herbivores and salicylate responses as a defense against pathogens is oversimplified, and we are still lacking a predictive framework for understanding the specificity of induction and ecological impacts (Fig. 4). Here we have tested hypotheses for the role of salicylate responses in mediating interactions and how specific pathogens may differentially affect chewing herbivores and aphids. For example, growth of S. exigua caterpillars was reduced on wild-type and salicylatedeficient plants infected with Pst, indicating a salicylateindependent mechanism of induced resistance. This effect is probably due to induction of a jasmonate response including PI activity by $P$ st. Thus, although the traditional view of chewing herbivores being impacted by jasmonate appears to hold, here resistance was induced by bacteria (Fig. 4). Other pathogens also activate and are impacted by jasmonate responses (Ton et al. 2002, Thaler et al. 2004).

In contrast to the effects of Pst, TMV infection positively affected caterpillar growth on wild-type plants capable of inducing salicylate responses, but a neutral to
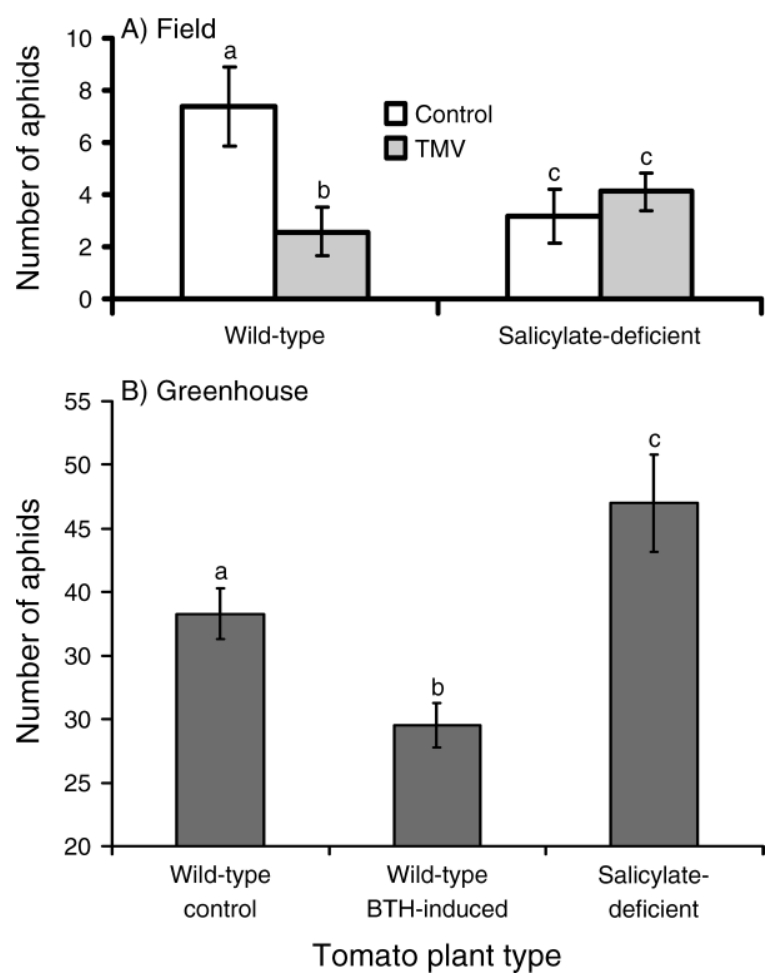

FIG. 3. (A) Abundance of naturally colonizing aphids on wild-type and salicylate-deficient plants with or without induction by tobacco mosaic virus (TMV) in the field, and (B) aphid reproduction on greenhouse grown wild-type plants (control), wild-type plants treated with BTH to induce the salicylate pathway (see Methods: Impacts of salicylate responses on aphids), and salicylate-deficient plants. BTH is benzothiadiazole, a salicylate mimic. Different letters indicate significant differences $(P<0.05)$ using contrasts. Shown are means $\pm \mathrm{SE}$. 
Damage Plant response Effects

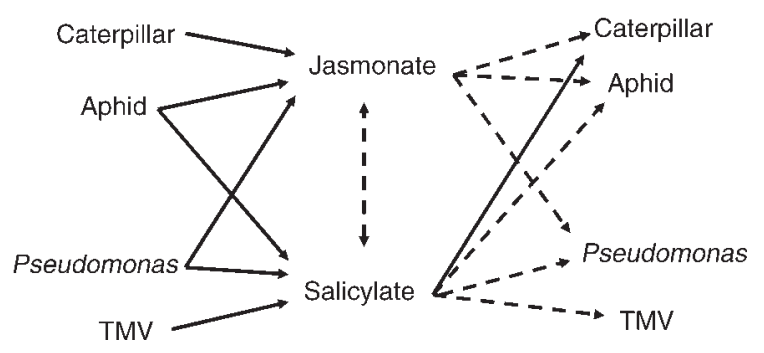

FIG. 4. A conceptual diagram for specificity in plant responses to insect and pathogen attackers and their effects on the various organisms via jasmonate and salicylate pathways. Solid arrows indicate positive effects, and dashed arrows indicate negative effects. The arrows are based primarily on work in this study and other work conducted on tomato and other Solanaceae (Raskin 1992, Fidantsef et al. 1999, Preston et al. 1999, Thaler 1999, Zhao et al. 2003). Effects independent of jasmonate and salicylate were evident but are not depicted here.

negative effect on caterpillar growth on the salicylatedeficient plants. Other manipulations of the salicylate pathway have also revealed positive effects of salicylate induction on S. exigua (Thaler 1999, Thaler et al. 1999, 2002). The reversal in the direction of the effect of TMV infection on wild-type and salicylate-deficient plants in our study emphasizes the indirect role of the salicylate pathway in interactions between pathogens and herbivores. When the salicylate pathway is disabled, the balance of pathogen-induced responses is negative for insects (Zarate et al. 2007). The benefit to caterpillars of being on a plant with a functional salicylate pathway is likely due to a weaker ability of this plant to induce the jasmonate pathway, which can clearly reduce caterpillar performance (Thaler et al. 1999). Here again, we offer a revision to the traditional dichotomous view of jasmonate and salicylate, with a pathogen-insect interaction being dependent on the salicylate pathway (Fig. 4).

Recent research demonstrates that aphids $M$. persicae and $M$. euphorbiae are negatively affected by both the jasmonate and salicylate pathways on tomato plants. The effect of the salicylate pathway appears to be more consistently negative than the effect of the jasmonate pathway (Thaler et al. 2001, Thaler 2002, Cooper et al. 2004, Cooper and Goggin 2005, Li et al. 2006; J. Thaler, personal observations). In field colonization experiments, we found that TMV infection had a negative effect on aphids on wild-type plants, whereas on salicylatedeficient plants there was no effect of infection. Similarly, in the lab, genetic (salicylate deficiency) and phenotypic (BTH application) manipulations showed nearly identical impacts, positive and negative, respectively, on aphids. The comparison of uninfected wildtype and salicylate-deficient plants in the field did not support this pattern; and this is likely due to the larger size and therefore greater attractiveness of wild-type plants.
In other plant systems, induction of the salicylate pathway by pathogens can have varying effects on aphid performance (McIntyre et al. 1981, Stout et al. 2006, Goggin 2007). Given that aphids are known to be inducers of, and are impacted by, both pathways, they evade the traditional jasmonate-salicylate dichotomy (Fig. 4). Like spider mites and other cell content feeders, phloem-sucking hemipterans may function as part herbivore and part pathogen (Walling 2000).

Other studies using signaling-pathway mutants have found evidence for the importance of jasmonatesalicylate signaling cross talk on the outcome of interactions between divergent plant parasites (Cui et al. 2005). For example, Zarate et al. (2007) showed that cross talk is an important determinant of the success of whiteflies feeding on Arabidopsis. Similarly, Spoel et al. (2007) showed that cross talk was important for the interaction between Pst and a fungal pathogen Alternaria brassicicola on Arabidopsis. How to grapple with this seeming complexity? We will build on some general modifications to the dichotomous view of jasmonate and salicylate (Moran and Thompson 2001, Ton et al. 2002, Cui et al. 2005, Musser et al. 2005).

Most arthropod herbivores probably will be classified as inducers of jasmonate only, or of jasmonate and salicylate together. Indeed, the joint activation of pathways may benefit the inducer because of crosspathway suppression, as has been demonstrated for a hemipteran (Zarate et al. 2007). In other systems it is more complicated, but salicylate-regulated products are still involved (Musser et al. 2005). Most microbial pathogens will be inducers of salicylate or of salicylate and jasmonate together. Again, some pathogens are clearly taking advantage of jasmonate-salicylate cross talk (e.g., Cui et al. 2005). We are not aware of any completely stealthy plant parasites evading both defense pathways, herbivores that only induce salicylate, or pathogens that only induce jasmonate. The differential impact of salicylate and jasmonate on guilds of herbivores and pathogens is more difficult to predict at this stage, as we have less knowledge about all of the responses cued by salicylate and jasmonate, and what makes plant parasites susceptible. Nonetheless, a priori predictions can be derived from our framework (Fig. 4) and tested with both genetic and phenotypic manipulations such as we have initiated here. Although the generality of this model across plant, herbivore, and pathogen systems is unclear, it appears that enemies can be predictably categorized along axes of the responses that they induce and the resistance traits to which they are susceptible.

\section{ACKNOWLEDGMENTS}

We thank Joey Dodgson, Alice Chen, Georg Jander, Andre Kessler, Celine Muis, Nile Kurashige, Matt Deeds, Jessica Nix, Danush Viswanathan, and Erin the cowboy for logistical help, and Sergio Rasmann, Ian Kaplan, and Monica Kersch-Becker for comments on the manuscript. Seeds of salicylate-deficient 
plants were provided by Jonathan Jones, and TMV was given by Laura Miller. Hormonal analyses were conducted in the Cornell Chemical Ecology Core Facility, with support from Paul Feeny, New Life Sciences Initiative, College of Agriculture and Life Sciences, Center for a Sustainable Future, Boyce Thompson Institute, and Departments of Ecology and Evolutionary Biology, Neurobiology and Behavior, Entomology, Plant Biology, and Horticulture. Funding was provided by NSERC of Canada, NSF DEB 0447550 (A. A. Agrawal), and the NRI-CSREES 2006-35302-17431 (J. S. Thaler).

\section{Literature Cited}

Bhattarai, K. K, Q. G. Xie, D. Pourshalimi, T. Younglove, and I. Kaloshian. 2007. Coil-dependent signaling pathway is not required for $M i-1$-mediated potato aphid resistance. Molecular Plant Microbe Interactions 20:276-282.

Boughton, A. J., K. Hoover, and G. W. Felton. 2006. Impact of chemical elicitor applications on greenhouse tomato plants and population growth of the green peach aphid, Myzus persicae. Entomologia Experimentalis et Applicata 120: $175-188$.

Brading, P. A., K. E. Hammond-Kosack, A. Parr, and J. D. G. Jones. 2000. Salicylic acid is not required for Cf-2- and Cf-9dependent resistance of tomato to Cladosporium fulvum. Plant Journal 23:305-318.

Chen, H., A. D. Jones, and G. A. Howe. 2006. Constitutive activation of the jasmonate signaling pathway enhances the production of secondary metabolites in tomato. FEBS [Federation of European Biochemical Societies] Letters 580: 2540-2546.

Cipollini, D. F., S. Enright, B. Traw, and J. Bergelson. 2004. Salicylic acid inhibits jasmonic acid-induced resistance of Arabidopsis thaliana to Spodoptera exigua. Molecular Ecology 13:1643-1653.

Cooper, W., and F. L. Goggin. 2005. The impact of jasmonateinduced defenses on the feeding behavior, fecundity, and mortality of the potato aphid, Macrosiphum euphorbiae. Entomologia Experimentalis et Applicata 115:107-115.

Cooper, W. C., L. Jia, and F. L. Goggin. 2004. Acquired and R-gene-mediated resistance against the potato aphid in tomato. Journal of Chemical Ecology 30:2527-2542.

Cui, J., A. K. Bahrami, E. G. Pringle, G. Hernandez-Guzman, C. L. Bender, N. E. Pierce, and F. M. Ausubel. 2005. Pseudomonas syringae manipulates systemic plant defenses against pathogens and herbivores. Proceedings of the National Academy of Sciences (USA) 102:1791-1796.

Doares, S. H., J. Narvaez-Vasquez, A. Conconi, and C. A. Ryan. 1995. Salicylic acid inhibits synthesis of proteinase inhibitors in tomato leaves induced by systemin and jasmonic acid. Plant Physiology 108:1741-1746.

Ellis, C., L. Karafyllidis, and J. G. Turner. 2002. Constitutive activation of jasmonate signaling in an Arabidopsis mutant correlates with enhanced resistance to Erysiphe cichoracearum, Pseudomonas syringae, and Myzus persicae. Molecular Plant-Microbe Interactions 15:1025-1030.

Farmer, E. E., R. R. Johnson, and C. A. Ryan. 1992. Regulation of expression of proteinase inhibitor genes by methyl jasmonate and jasmonic acid. Plant Physiology 98: 995-1002.

Fidantsef, A. L., M. J. Stout, J. S. Thaler, S. S. Duffey, and R. M. Bostock. 1999. Signal interactions in pathogen and insect attack: Expression of lipoxygenase, proteinase inhibitor II, and pathogenesis-related protein P4 in the tomato, Lycopersicon esculentum. Physiological and Molecular Plant Pathology 54:97-114.

Goggin, F. L. 2007. Plant-aphid interactions: molecular and ecological perspectives. Current Opinion in Plant Biology 10: 399-408.

Hatcher, P. E. 1995. Three-way interactions between plant pathogenic fungi, insect herbivores, and their host plants. Biological Reviews 70:639-694.
Howe, G. A. 2004. Jasmonates as signals in the wound response. Journal of Plant Growth Regulation 23:223-237.

Inbar, M., H. Doostdar, D. Gerling, and R. T. Mayer. 2001. Induction of systemic acquired resistance in cotton by BTH has a negligible effect on phytophagous insects. Entomologia Experimentalis et Applicata 99:65-70.

Inbar, M., H. Doostdar, R. M. Sonoda, G. L. Leibee, and R. T. Mayer. 1998. Elicitors of plant defensive systems reduce insect densities and disease. Journal of Chemical Ecology 24: $135-149$.

Kaloshian, I., and L. L. Walling. 2005. Hemipterans as plant pathogens. Annual Review of Phytopathology 43:491-521.

Karban, R., R. Adamchak, and W. C. Schnathorst. 1987. Induced resistance and interspecific competition between spider mites and a vascular wilt fungus. Science 235:678-680.

Kessler, A., R. Halitschke, and I. T. Baldwin. 2004. Silencing the jasmonate cascade: Induced plant defenses and insect populations. Science 305:665-668.

Li, Q., Q.-G. Xie, J. Smith-Becker, D. A. Navarre, and I. Kaloshian. 2006. Mi-1-mediated aphid resistance involves salicylic acid and mitogen-activated protein kinase signaling cascades. Molecular Plant-Microbe Interactions 19:655-664.

Lin, L., T. Shen, Y. Chen, and S. Hwang. 2008. Responses of Helicoverpa armigera to tomato plants previously infected by TMV or damaged by $H$. armigera. Journal of Chemical Ecology 34:353-361.

McIntyre, J. L., J. A. Dodds, and J. D. Hare. 1981. Effects of localized infections of Nicotiana tobacum by tobacco mosaic virus on systemic resistance against diverse pathogens and an insect. Phytopathology 71:297-301.

Moran, P. J., and G. A. Thompson. 2001. Molecular responses to aphid feeding in Arabidopsis in relation to plant defense pathways. Plant Physiology 125:1074-1085.

Musser, R. O., D. F. Cipollini, S. M. Hum-Musser, S. A. Williams, J. K. Brown, and G. W. Felton. 2005. Evidence that the caterpillar salivary enzyme glucose oxidase provides herbivore offense in solanaceous plants. Archives of Insect Biochemistry and Physiology 58:128-137.

O'Donnell, P. J., E. Schmelz, A. Block, O. Miersch, C. Wasternack, J. B. Jones, and H. J. Klee. 2003. Multiple hormones act sequentially to mediate a susceptible tomato pathogen defense response. Plant physiology 133:1181-1189.

Ohgushi, T. 2005. Indirect interaction webs: Herbivore-induced effects through trait change in plants. Annual Review of Ecology, Evolution and Systematics 36:81-105.

Pan, X., R. Welti, and X. Wang. 2001. Simultaneous quantification of major phytohormones and related compounds in crude plant extracts by liquid chromatographyelectrospray tandem mass spectrometry. Phytochemistry 69: 1773-1781.

Preston, C. A., C. Lewandowski, A. J. Enyedi, and I. T. Baldwin. 1999. Tobacco mosaic virus inoculation inhibits wound-induced jasmonic acid-mediated responses within but not between plants. Planta 209:87-95.

Raskin, I. 1992. Role of salicylic-acid in plants. Annual Review of Plant Physiology 43:439-463.

Rodriguez-Saona, C., J. A. Chalmers, S. Raj, and J. S. Thaler. 2005. Induced plant responses to multiple damagers: differential effects on an herbivore and its parasitoid. Oecologia 143:566-577.

Spoel, S. H., J. S. Johnson, and X. Dong. 2007. Regulation of tradeoffs between plant defenses against pathogens with different lifestyles. Proceedings of the National Academy of Sciences (USA) 104:18842-18847.

Stout, M. J., J. S. Thaler, and B. Thomma. 2006. Plantmediated interactions between pathogenic microorganisms and herbivorous arthropods. Annual Review of Entomology 51:663-689.

Stout, M. J., K. V. Workman, R. M. Bostock, and S. S. Duffey. 1998. Specificity of induced resistance in the tomato, Lycopersicon esculentum. Oecologia 113:74-81. 
Thaler, J. S. 1999. Jasmonic acid mediated interactions between plants, herbivores, parasitoids, and pathogens: A review of field experiments in tomato. Pages 319-334 in A. A. Agrawal, S. Tuzun, and E. Bent, editors. Induced plant defenses against pathogens and herbivores: biochemistry, ecology, and agriculture. American Phytopathological Society Press, St. Paul, Minnesota, USA.

Thaler, J. S. 2002. Effect of jasmonate-induced plant responses on the natural enemies of herbivores. Journal of Animal Ecology 71:141-150.

Thaler, J. S., A. L. Fidantsef, and R. M. Bostock. 2002. Antagonism between jasmonate- and salicylate-mediated induced plant resistance: Effects of concentration and timing of elicitation on defense-related proteins, herbivore, and pathogen performance in tomato. Journal of Chemical Ecology 28:1131-1159.

Thaler, J. S., A. L. Fidantsef, S. S. Duffey, and R. M. Bostock. 1999. Trade-offs in plant defense against pathogens and herbivores: A field demonstration of chemical elicitors of induced resistance. Journal of Chemical Ecology 25:15971609.

Thaler, J. S., B. Owen, and V. J. Higgins. 2004. The role of the jasmonate response in plant susceptibility to diverse pathogens with a range of lifestyles. Plant Physiology 135:530-538.

Thaler, J. S., M. J. Stout, R. Karban, and S. S. Duffey. 1996. Exogenous jasmonates simulate insect wounding in tomato plants (Lycopersicon esculentum) in the laboratory and field. Journal of Chemical Ecology 22:1767-1781.

Thaler, J. S., M. J. Stout, R. Karban, and S. S. Duffey. 2001. Jasmonate-mediated induced plant resistance affects a community of herbivores. Ecological Entomology 26:312324.

Thomma, B., K. F. M. Tierens, I. Penninckx, B. Mauch-Mani, W. F. Broekaert, and B. P. A. Cammue. 2001. Different micro-organisms differentially induce Arabidopsis disease response pathways. Plant Physiology and Biochemistry 39: 673-680.

Thompson, G. A., and F. L. Goggin. 2006. Transcriptomics and functional genomics of plant defence induction by phloem-feeding insects. Journal of Experimental Botany 57: 755-766.

Ton, J., J. A. Van Pelt, L. C. Van Loon, and C. M. J. Pieterse. 2002. Differential effectiveness of salicylate-dependent and jasmonate/ethylene-dependent induced resistance in Arabidopsis. Molecular Plant-Microbe Interactions 15:27-34.

Tornero, P., J. Gadea, V. Conejero, and P. Vera. 1997. Two PR-1 genes from tomato are differentially regulated and reveal a novel mode of expression for a pathogenesis-related gene during the hypersensitive response and development. Molecular Plant-Microbe Interactions 10:624-634.

Van Zandt, P. A., and A. A. Agrawal. 2004. Community-wide impacts of herbivore-induced plant responses in milkweed (Asclepias syriaca). Ecology 85:2616-2629.

Viswanathan, D. V., A. J. T. Narwani, and J. S. Thaler. 2005. Specificity in induced plant responses shapes patterns of herbivore occurrence on Solanum dulcamara. Ecology 86: 886-896.

Walling, L. L. 2000. The myriad plant responses to herbivores. Journal of Plant Growth Regulation 19:195-216.

Zarate, S. I. L. A. Kempema, and L. L. Walling. 2007. Silverleaf whitefly induces salicylic acid defenses and suppresses effectual jasmonic acid defenses. Plant Physiology 143:866-875.

Zhao, Y. F., R. Thilmony, C. L. Bender, A. Schaller, S. Y. He, and G. A. Howe. 2003. Virulence systems of Pseudomonas syringae pv. tomato promote bacterial speck disease in tomato by targeting the jasmonate signaling pathway. Plant Journal 36:485-499.

\section{APPENDIX}

Effects of various factors on mass of Spodoptera exigua and proteinase inhibitor activity (Ecological Archives E091-075-A1). 